\title{
O Curso de Atençáo Integrada às Doenças Prevalentes na Infância: uma experiência no Internato de Saúde Coletiva do Centro Universitário de Volta Redonda - UniFOA
}

\section{The Course on Integrated Management of Childhood Illness: An Experience in the Internship in Public Health from University Center of Volta Redonda - UniFOA}

Márcia Dorcelina Trindade Cardoso ${ }^{1}$ Maria Auxiliadora Motta Barreto ${ }^{2}$

\section{Resumo}

A Atenção Integrada as Doenças Prevalentes na Infância (AIDPI) constitui uma estratégia formulada pela Organização Mundial de Saúde (OMS) e Fundo das Naçóes Unidas para a Infância (UNICEF), baseada em evidências cientificas, que foi adotada pelo Ministério da Saúde do Brasil (MS) em 1996, com algumas adaptaçôes, de acordo com as características epidemiológicas e as normas nacionais do Programa de Atençáo à Criança. Desde 1997, a AIDPI, foi implantada progressivamente em vários Estados e Universidades brasileiras. Em 2000, o Centro Universitário de Volta Redonda (UniFOA), introduziu a capacitação em AIDPI no Internato de Saúde Coletiva do Curso de Medicina, almejando uma melhor preparação discente, segundo os preceitos curriculares para a formação do médico generalista, com atividades práticas preceptoradas, nas Unidades de Saúde da Família (USF). Após a capacitação aconteceram, mudanças significativas no resultado dos testes usados para mensuraçáo do conhecimento dos discentes quanto, à utilização de critérios padronizados e simplificados, de avaliação, classificação e tratamento de acometimentos prevalentes na infância, propiciando ainda detecção precoce de intercorrências com possibilidade de risco de vida.

Palavras-chave: AIDPI; discentes; medicina preventiva.

\begin{abstract}
The Integrated Management of Childhood Illness (AIDPI) is a strategy formulated by the World Health Organization (WHO) and United Nations Children's Fund (UNICEF), based on scientific evidence, which was adopted by the Brazilian Ministry of Health (MS) in 1996, with some adjustments, according to the epidemiological and national standards of the Program for Children. Since 1997, AIDPI was implemented progressively in several Brazilian states and universities. In 2000, the Centro Universitário de Volta Redonda (UniFOA), introduced AIDPI training to Internship in Public Health of the Medical Program, aiming to better prepare students, according to the precepts of the curriculum for training general practitioners with practical activities preceptors, in Family Health Units (USF). After the training occurred, significant changes in the results of tests used to measure the students' knowledge as to the use of standardized criteria and simplified evaluation, classification and treatment of prevalent childhood affections, yet providing early detection of complications with risk of life.
\end{abstract}

Keywords: AIDPI, medical staff, preventive medicine

\footnotetext{
${ }^{1}$ Mestranda do Programa de Mestrado em Ensino em Ciência da Saúde e do Meio Ambiente - UniFOA

${ }^{2}$ Docente do Programa de Mestrado em Ensino em Ciência da Saúde e do Meio Ambiente - UniFOA, Doutora em Psicologia como Profissáo e Ciência, Mestre em Educação, Psicóloga.
} 


\section{INTRODUÇÃO}

Com a elevada morbimortalidade em crianças menores de 5 anos, por doenças preveníveis, nos paises em desenvolvimento, e a necessidade de reduzir a mortalidade infantil, embora nem todas estas mortes possam ser evitadas, a prevenção e o cuidado associados a medidas simples - como o aconselhamento das mães, vem sendo cada vez mais necessários para reduzir este indicador (OPAS, 2002 e 2004). A Organização Mundial de Saúde (OMS), o Fundo das Naçóes Unidas para a Infância (UNICEF) e a Organização Pan Americana de Saúde (OPAS) elaboraram a Estratégia Atenção Integrada as Doenças Prevalentes na Infância (AIDPI), incorporando diversas outras estratégias já existentes e utilizadas para melhorar a assistência médica e fortalecer a promoção da saúde desta população (BENGUIGY, 1997).

A estratégia AIDPI foi idealizada com o objetivo de abordar a criança "como um todo" ampliando a consideração do paciente, não se atendo exclusivamente ao "problema de saúde”. Alia, de forma sistemática, os principais fatores que afetam a saúde das crianças para detectar e tratar qualquer "sinal geral de perigo" ou "doença específica", integrando ações curativas com medidas de prevenção e promoção da saúde; reduzindo a mortalidade infantil e contribuindo de modo significativo para que a criança atinja seu potencial máximo de crescimento e desenvolvimento, sobretudo em países emergentes. A estratégia tem, por finalidade, trabalhar a criança em sua integralidade, aperfeiçoando o relacionamento humano, os vínculos, a criação de laços de compromisso e de co-responsabilidade dos profissionais de saúde com a comunidade, caracterizando-se pela consideração simultânea e integrada do conjunto de doenças de maior prevalência na infância, substituindo o enfoque tradicional que busca abordar cada doença isoladamente, como se ela fosse independente das demais doenças. (ANDRADE, 1998; MENDES, 1998).

A estratégia AIDPI foi adotada pelo Ministério da Saúde-MS em 1996, e desde então, vem sendo progressivamente implantada em municípios, estados e universidades. As universidades, em particular, têm papel fundamental na formação dos futuros profissionais de saúde que irão atuar nos cuidados com crianças (GRISI, OKAY E SPEROTTO, 2005). No Brasil, atualmente, algumas universidades, em estados como o Ceará e Pernambuco, continuam desenvolvendo a estratégia AIDPI no curso médico, assim como, irregularmente, algumas universidades do estado do Rio de Janeiro.

No UniFOA, as atividades de desenvolvimento do curso de AIDPI no Curso de Medicina consistiram na capacitação de alguns docentes da disciplina de Pediatria, alguns destes capacitados pelo Ministério da Saúde e outros por facilitadores capacitados pelo Ministério, e de todos os preceptores de
Saúde Coletiva, que foram capacitados por facilitadores.

O Material usado no curso foi reproduzido pelo UniFOA, sendo que cada aluno recebeu, apostilas para usar durante o mesmo. O Curso AIDPI consiste em aplicação de um pré teste padronizado, antes do inicio das aulas teóricas, exercícios-casos clínicos, dramatizaçôes, exposição de vídeo e atividades práticas no ambulatório da Unidade Saúde da Família, e práticas hospitalares. Estes alunos usam um protocolo padronizado para o atendimento de todas as crianças menores de 5 anos de idade e, ao final do curso, respondem a um pós teste para avaliar o aprendizado.

\section{MATERIAL E MÉTODOS}

Foi realizado um estudo retrospectivo, quantitativo, no período de novembro de 2000 a dezembro de 2008, tendo sido avaliados 600 pré testes, respondidos no início do curso e 600 pós testes, respondidos ao final do curso pelos alunos do internato de Saúde Coletiva do Curso de Medicina do Centro Universitário de Volta Redonda - UniFOA.

Os profissionais envolvidos no Curso de capacitação na estratégia AIDPI são Facilitadores e Docentes, que fizeram curso especifico em 1999, promovido pelo Ministério da Saúde e Secretarias de Saúde, Estadual e Municipal, através do envolvimento de Universidades Públicas e Privadas, que disponibilizaram os docentes. A duração deste curso para facilitadores foi de 10 a 12 dias, com ênfase nas bases técnicas de AIDPI, na parte pedagógica e as técnicas de comunicação. Os docentes, neste caso, são do Curso de Medicina de uma instituição de ensino médico, que participam da inclusão da estratégia AIDPI no currículo do curso médico.

Os alunos foram divididos em grupos de quinze, e o curso teve duração de 60 horas, com atividades práticas nas Unidades de Saúde da Família, onde as atividades do internato de Saúde Coletiva são desenvolvidas com acompanhamento de um preceptor já capacitado em AIDPI, numa proporçáo de um preceptor para cada grupo de cinco alunos. A duração do curso é de 15 dias, e as atividades práticas são desenvolvidas durante oito semanas, nas Unidades de Saúde da Família do município. Algumas aulas práticas também aconteceram em Hospital, na enfermaria de Pediatria, alojamento conjunto, Unidade de Tratamento Intensivo e Unidade Intermediária, além do Pronto Socorro Pediátrico. As atividades teóricas ocorreram com leitura do texto e realização de exercícios - casos clínicos, além de ser realizada a exposição de vídeo e atividades de dramatização. Durante as atividades práticas, cada aluno deve preencher um total de 40 protocolos padronizados de atendimento pela estratégia AIDPI, de acordo com a faixa etária da criança atendida, de 0 a 2 meses, e de 2 meses a 5 anos. 


\section{ANÁLISE DOS DADOS E RESULTADOS}

Os alunos participantes, também fazem uma avaliação oral e escrita do curso. Os testes respondidos pelos alunos foram corrigidos de acordo com padráo estabelecido pelos autores do curso AIDPI (PAIXÃO e AMARAL, 2004).

Analisando os resultados dos testes observamos que no pré-teste o nível de acertos foi de $60 \%$, enquanto que no pós-teste o nível de acertos alcançou $90 \%$, num grupo que esteve presente em $100 \%$ das aulas. Portanto, ocorreu um aumento de 30\% no nível de acertos.

Isso indica que, após o curso, os alunos tiveram mais capacidade crítica e maior facilidade para diagnosticar os problemas de saúde presentes nos casos clínicos, para tratar os enfermos e orientar os familiares. A atuação mais qualificada dos alunos no pós-teste pode ser atribuída à criação de uma seqüência de avaliação da criança, o que facilita a abordagem e o desenvolvimento de um raciocínio clínico.

\section{CONSIDERAÇÓES FINAIS}

A disciplina de Saúde Coletiva do Curso de Medicina do UniFOA, é ministrada no $1^{\circ}$ e $2^{\circ}$ períodos e depois no $9^{\circ}, 10^{\circ}, 11^{\circ}, 12^{\circ}$ períodos, desde 2000 , iniciando as mudanças no currículo do Curso de medicina, de acordo com a Lei de Diretrizes e Bases do Ensino Médico no Brasil. Como os quatro últimos períodos são desenvolvidos em Unidades de Saúde da Família, o centro universitário optou por preparar os alunos para as atividades na rede básica de Saúde do município de Volta Redonda e o curso de Atenção Integrada à Doenças Prevalentes na Infância - AIDPI foi uma destas atividades.

A estratégia AIDPI é reconhecida internacionalmente, como a intervençáo que tem maior potencial de beneficio para a saúde da criança. Desde sua implantação nas Américas em 1996, a maioria dos países o tem adotado como estratégia para alcançar os objetivos de reduçáo de morbidade e mortalidade infantil e oferecer uma melhor qualidade de atenção, tanto nos serviços de saúde, quanto na comunidade e no lar.

A partir desta capacitação, observamos que estes alunos desenvolveram mais habilidade na análise e orientaçáo as mães quanto às imunizaçóes das crianças. A simples avaliação da frequêencia respiratória e a possibilidade de uma conduta rápida e adequada às crianças com doenças respiratórias asseguraram aos alunos uma maior segurança nas consultas. Algumas questôes dos testes abordavam o cuidado com a criança saudável e doente, e muitos dos alunos apresentaram dificuldades em orientar as mães, após o curso estas dificuldades foram esclarecidas e a habilidade desenvolvida.

\section{REFERÊNCIAS}

AMARAL, J. J. F. do e PAIXÃO, A. C. da. AIDPI para o Ensino Médico: Manual de Apoio. 3.ed. Brasília: Organização Pan-Americana da Saúde, 2004.

ANDRADE, F.M. Oliveira. O Programa Saúde da Família no Ceará: uma análise de sua estrutura e funcionamento. Fortaleza, 1998 220p.

BENGUIGY.Y. Atençáo Integrada às Doenças Prevalentes na Infância. Washington, DC: Organização PanAmericana da Saúde, 1997.

GRISI.S.; OKAY.Y.; SPEROTTO.G. Estratégia Atenção Integrada às Doenças Prevalentes da Infância. AIDPI. Washington, DC: Organização PanAmericana da Saúde, 2005.

MENDES. E. V. A Organizaçáo da Saúde no Nível Local. São Paulo, 1998. p. 38-39.

ORGANIZAÇÃO PANAMERICANA DA SAÚDE. AIDPI para o ensino médico. Brasília, DF, 2002.

ORGANIZAÇÃO PANAMERICANA DA SAÚDE. Atenção Integrada às Doenças Prevalentes na Infância. AIDPI: Avaliação nas Unidades de Saúde. Brasilia, DF, 2002.

\section{Endereço para Correspondência:}

Márcia Dorcelina Trindade Cardoso - m.dorcelina@hotmail.com Centro Universitário de Volta Redonda - Campus Três Poços Av. Paulo Erlei Alves Abrantes, no 1325, Três Poços - Volta Redonda / RJ CEP: $27240-560$ 